\title{
Misallocation Costs of Digging Deeper into the Central Bank Toolkit *
}

\author{
Robert Kurtzman ${ }^{\dagger 1}$ and David Zeke $\$ 2$ \\ ${ }^{1}$ Federal Reserve Board of Governors \\ ${ }^{2}$ University of Southern California
}

May 4, 2017

\begin{abstract}
This paper examines the potential misallocation of resources induced by Central Bank large-scale asset purchases, particularly the purchase of corporate bonds of nonfinancial firms, through their heterogeneous effect on firms' cost of capital. First, we analytically demonstrate the mechanism in a static model with heterogeneous agents. We then evaluate the misallocation of resources induced by corporate bond buys and the associated output losses in a calibrated DSGE model of which Gertler and Karadi (2013) is a special case.
\end{abstract}

*The views expressed in this paper are solely the responsibility of the authors and should not be interpreted as reflecting the views of the Board of Governors of the Federal Reserve System or of anyone else associated with the Federal Reserve System. We would like to thank those at the Macroeconomic Model Data Base for providing their code, which we adapted. All mistakes are our own.

${ }^{\dagger}$ robert.j.kurtzman@frb.gov

†zeke@usc.edu 


\section{Introduction}

Central banks, such as the Bank of Japan (BOJ), the European Central Bank (ECB), and the Federal Reserve (the Fed) have used large-scale asset purchases (LSAPs) as a policy tool once they have reduced the short rate under their control to its effective lower bound. ${ }^{1}$ While the BOJ, the ECB, and the Fed purchased government bonds as part of their LSAP programs, as they have chosen to buy other assets, their choices have differed: between them, the different Central Banks have purchased mortgage backed securities, corporate bonds, exchange-traded funds, and other assets. Yet, there is little theory to guide Central Banks on whether there are aggregate costs to purchasing some assets rather than others.

This paper takes a step to address this gap in the literature, focusing specifically on the costs associated with large-scale purchases of nonfinancial corporate bonds. Purchases of corporate bonds (and other corporate securities) may reduce future expected returns by more on those securities than others not purchased, and potentially create distortions in the cost of capital among firms. Our work builds a simple theory of LSAPs with this mechanism present to deliver results as to how large-scale purchases of corporate bonds affects the allocation of capital among firms. We then introduce the key elements of our simple model into a New-Keynesian DSGE model. With our calibrated DSGE model, we quantify the potential misallocative effects of large-scale purchases of nonfinancial firm corporate bonds.

To demonstrate the economic mechanism at work within our DSGE model, the first part of the paper takes a static model of firm dynamics with a financial intermediary sector and demonstrates the conditions under which a large-scale purchase of nonfinancial firm corporate bonds by the government induces a misallocation of resources. The model allows us to separate two effects of a shock to interest rates that lower rates for one set of firms (firms issuing highly-rated corporate bonds, which we denote as large firms) more than another (which we denote as small firms): 1) Effect on the allocation of capital 2) Effect on the aggregate capital stock. We isolate the key elements of our model that govern the size of each effect. ${ }^{2}$

\footnotetext{
${ }^{1}$ Such large-scale asset purchases are often referred to as quantitative easing policies (QE).

${ }^{2}$ It is possible to use a large-scale purchase of corporate bonds to either reduce a misallocation
} 
The static model we build is a simplified, static version of Gertler and Karadi (2013), wherein we introduce two additional model elements. ${ }^{3}$ The first of the two additional model elements is heterogeneity in production among multiple "groups" of firms. Specifically, we allow there to be two (or more) types of intermediate good firms that have similar production technologies. Their weighted sales are aggregated into a single intermediate good that is used in production of the final good.

Second, we introduce a regulatory constraint which allows for richer heterogeneity in spreads than in Gertler and Karadi (2013). The regulatory constraint makes it more costly for banks to hold corporate bonds than government bonds (and bank loans to small firms even more costly than corporate bonds). Policies such as the Liquidity Coverage Ratio that favor Treasuries relative to corporate debt (relative to bank loans) are the realistic counterpart to this model constraint. ${ }^{4}$ Additionally, the regulatory constraint discourages the concentration of certain classes of private securities. In equilibrium, this constraint induces asymmetric effects in the credit spread response of purchasing debt of firms relative to that of the government.

In our model, when the central bank buys the securities of one set of firms, it lowers the cost of capital for that set of firms by more than other sets of firms, all else equal. When the government buys government bonds, if spreads between loans to various types of firms (large and small firms, for instance) are small in steady state, the government reduces the cost of capital for all firms approximately

or increase a misallocation. However, we focus on the latter effect in explaining the mechanism, guided by our calibration.

${ }^{3}$ In Gertler and Karadi (2013), banks are essentially collateral constrained when the economy is hit by a bad enough shock, inducing credit spreads on private and public bonds to rise inefficiently, and thus distorting investment inefficiently. Credit spreads on private bonds, due to the fact that debt is perfectly state-contingent, are to a first-order driven by the market value of capital and not a friction between the nonfinancial firm and the intermediary. Quantitative easing policies by the Central Bank can reduce credit spreads and increase investment and output, even if the Central Bank itself inefficiently intermediates financial transactions. Our static model is different in that prices are not sticky and the net worth of banks is exogenous. Of course, our static model is different as well in that it is static and not a DSGE model. We also simplify the problem of the representative consumer.

${ }^{4}$ Details of the Liquidity Coverage Ratio can be found at: https://www.occ.gov/ news-issuances/bulletins/2014/bulletin-2014-51.html 
evenly. ${ }^{5}$ Hence, in equilibrium, there is an additional effect on the allocation of resources from a corporate bond purchase that does not occur to the same degree from a government bond purchase. Specifically, following Gertler and Karadi (2011) and Gertler and Karadi (2013), such heterogeneous effects are due to the constraints faced by a financial intermediary who facilitates the transfer of funds from households to firms. Such a framework thus endogenizes the heterogeneous effect on borrowing costs from a large-scale purchase of nonfinancial firm corporate bonds.

We build on the work of Gertler and Karadi (2013), as (our understanding is) their framework is widely used in studying quantitative easing policies across Central Banks. The additional model assumptions of the first part of the paper are motivated by two strands of the literature. The first strand of the literature builds on the results of Krishnamurthy and Vissing-Jorgensen (2011), among others, who demonstrate that there are price effects of Central Bank bond buys that are more pronounced for the securities purchased than other securities. The literature suggests purchases of corporate bonds will directly reduce the spread on corporate bonds, but the effect of such a purchase on other assets such as the interest rate at which banks lend will be smaller. This incomplete pass-through of interest rates leads to asymmetric effects on the interest rates at which firms can borrow, and therefore their cost of capital. In the simple model, LSAPs can induce heterogeneous shock to borrowing costs, and this shock has implications for the allocation of capital.

The second strand of the literature builds on the results of Gilchrist, Sim, and Zakrajsek (2013) and Midrigan and Xu (2014), among others, who present models wherein financial frictions increase the dispersion in borrowing costs and distort the input decisions of firms away from what is socially efficient. Such models have macroeconomic implications, as shocks that result in a worsening of such frictions reduce total factor productivity and aggregate output. ${ }^{6}$

\footnotetext{
${ }^{5}$ There can be a non-negligible misallocation effect from purchasing government bonds if there is a sizable spread between small and large firms in steady state, although the effect is less pronounced than when the government buys the bonds of large firms.

${ }^{6}$ In Gilchrist, Sim, and Zakrajsek (2013), the financial frictions are not explicitly modeled but it is assumed that financial frictions induce the dispersion in borrowing. Further, in the robustness section of Midrigan and $\mathrm{Xu}$ (2014), there is an evaluation of how heterogeneity in borrowing rates induce a misallocation, although the focus of the paper is on how a worsening of financial frictions can induce a misallocation. Also, it is important to note that financial frictions can also distort entry
} 
The second part of this paper quantifies the misallocation effects of large-scale asset purchases of bonds issued by one set of firms (large firms) and not another set of firms (small firms) in a calibrated, DSGE model similar to our two-period model but now with the model elements in Gertler and Karadi (2013) that we did not include in our static model: Sticky prices, endogenous net worth of banks, and a representative household with habits that can hold bonds facing a holding cost. In the DSGE model, the response of credit spreads to an asset purchase are not only heterogeneous as in our static model, but also time-varying. We calibrate the model following Gertler and Karadi (2013), picking reasonable values for the new parameters we introduce based on U.S. data. A QE policy in which the Central Bank purchases public debt produces a positive, large effect on investment and output after a bad shock. However, a QE policy in which the Central Bank purchases the debt of large firms - although potentially inducing a similar effect on output reduces the response of investment for small firms whose debt is not purchased by the Central Bank and induces a non-negligible misallocation of resources. ${ }^{7}$

The rest of the paper, after the literature review below, follows as such. Section 2 presents results from the simple model. Section 3 describes the DSGE model, focusing on how we amend Gertler and Karadi (2013) and how we calibrate remaining parameters, and assesses the quantitative implications of large-scale purchases of nonfinancial firm corporate bonds. In Section 4, we conclude.

\subsection{Related Literature}

This paper is related to two main strands of the literature. The first strand of the literature attempts to embed quantitative easing policies in macroeconomic models to analyze the channels through which quantitative easing affects the economy. In the quantitative section of our paper, we stick closely to Gertler and Karadi (2013), only amending it in ways to make the economic point of interest. This paper could be grouped, largely, into an "imperfect asset-substitutability" channel of monetary policy. Other papers in this literature, such as He and Krishnamurthy (2013) and and technology adoption in Midrigan and $\mathrm{Xu}$ (2014).

${ }^{7}$ In Gertler and Karadi (2013), purchasing private sector debt increases output more than purchasing government sector debt. We still find there to be large positive effects on output from purchase private sector debt, but these affects are dampened due to the misallocation effect. 
Cúrdia and Woodford (2015), also emphasize the role of financial market imperfections in making QE effective. ${ }^{8}$

Our paper is also related to the literature on how misallocation affects the macroeconomy, a large literature built on the work of Hopenhayn and Rogerson (1993) and Hsieh and Klenow (2009), among many others. The closest papers to ours are that of Midrigan and Xu (2014) and Gilchrist, Sim, and Zakrajsek (2013) as they study how financial frictions that induce a misallocation (and result in a wider dispersion in credit spreads) affect the macroeconomy.

\section{Demonstrating the Mechanism in a Simple Model}

We begin by highlighting the main mechanism in our paper within a static framework of firm capital choice and financing. The model details how the capital decisions of heterogeneous firms are affected by the financing environment, and how central bank LSAP change the allocation of capital and affect macroeconomic aggregates.

Heterogeneous firms choose their capital to maximize profits, but their capital choice and profits are affected by their (heterogeneous) cost of capital. Firms must finance their capital via constrained financial intermediaries. Purchases of securities by the central bank will loosen the financial intermediary's collateral constraint, lowering spreads and therefore firms' cost of capital. Purchases of corporate securities, due to a regulatory constraint that enters the financial intermediary's problem, will lower spreads for purchased securities by more than others.

The model allows us to identify the key parameters that govern the two real effects resulting from central bank purchases of corporate securities: 1) Effects on the allocation of capital 2) Effects on the aggregate capital stock.

\footnotetext{
${ }^{8}$ There is a growing literature addressing different channels in which QE policies affect the economy. In Bhattarai, Eggertsson, and Gafarov (2015), the authors model the "signaling channel" of quantitative easing policies. In Greenwood and Vayanos (2014), the authors outline the "durationrisk channel" of quantitative easing policies. Other channels have been highlighted in the literature on quantitative easing, such as the prepayment-risk channel and open-economy channels.
} 


\subsection{Model and Equilibrium}

\subsubsection{Production Environment}

The model consists of heterogeneous intermediate good firms and a representative final good firm, financial intermediary, capital producer, and household. There are $J$ continuums of intermediate good firms. Intermediate good firms are indexed by $i$, and the continuum they belong to by $j$. The total mass of firms is normalized to $1\left(\sum_{j=1}^{J} \int_{i \in j} d i=1\right)$. Each intermediate good firm, $i$, produces a differentiated good using capital, $k_{i}$, with technology $y_{i}=A_{i} k_{i}^{\alpha}$.

The final good is produced from intermediate goods with technology $Y=$ $\left(\int_{i} y_{i}^{\rho} d i\right)^{\frac{1}{\rho}}$. The final good can either be consumed or used to produce capital. Capital can be produced from the final good with technology which requires $\phi^{K}(K)$ units of the final good to produce $K$ units of capital, where $\phi^{K}(K)$ is weakly convex. Therefore the clearing condition for the final good is $Y=C+\phi^{K}(K)$.

Finally, intermediate good firms, in total, cannot use more of the capital good than is produced: $K \geq \int_{i} k_{i} d i$.

\subsubsection{Final Good Firms, Capital Producers, Households}

The final good sector is competitive. Thus, it earns zero profits and maximizes the problem: ${ }^{9}$

$$
\max _{y_{i}}\left(\int y_{i}^{\rho} d i\right)^{\frac{1}{\rho}}-\int_{i} p_{i} y_{i} d i
$$

From (1), we can obtain the standard expression for the price of intermediate good firms:

$$
p_{i}=\left(\frac{y_{i}}{Y}\right)^{\rho-1} .
$$

Aggregate capital is chosen to maximize profits of a firm which converts the final good into capital:

$$
\max _{K} Q K-\phi^{K}(K)
$$

\footnotetext{
${ }^{9}$ The price of the final good is the numeraire.
} 
where $Q$ is the price of capital, shared across firms. We assume that $\phi^{K}=\frac{h_{k} K^{1+b_{k}}}{1+b_{k}}$, where $h_{k}$ is a parameter that affects the level of the cost of producing capital, while $b_{k}$ is a parameter that affects the convexity of the cost of producing capital.

Households are the residual claimants of all profits by firms or intermediaries, and there is a representative household which consumes the final good. Households can also lend or borrow from the financial intermediary at a gross interest rate $r$. Households make consumption and lending decisions to maximize consumption subject to their budget constraint:

$$
C+B_{h}=B_{h} r+X
$$

where $B_{h}$ is the net lending of the household to the financial intermediary and $X$ is the sum of the household endowment and profits of intermediate good firms, financial intermediaries, and capital producing firms. In equilibrium, the gross return on household lending must be $r=1$, otherwise the household would want to lend or borrow infinite amounts to financial intermediaries. ${ }^{10}$

\subsubsection{Intermediate Good Firms}

Intermediate good firm $i$ maximizes profits, defined as revenues from production less expenditures on capital:

$$
\max _{k_{i}} \frac{p_{i} y_{i}}{\tau_{i}^{k}}-r_{i} Q k_{i}
$$

where $\tau_{i}^{k}$ is an exogenous wedge which represent distortions or inefficiencies in capital allocation not included in the model. Capital expenditures by the firm must be financed, and $r_{i}$ is the gross interest rate at which a firm can borrow (the 'cost of capital'). This maximization problem yields first-order condition for capital:

$$
k_{i}=\left(\frac{\alpha \rho Y^{1-\rho} A_{i}^{\rho}}{\tau_{i}^{k} r_{i} Q}\right)^{\frac{1}{1-\alpha \rho}} .
$$

\footnotetext{
${ }^{10}$ Since this is a static model, all of the lending is happening within the period.
} 


\subsubsection{Financial Intermediation}

As firm capital must be financed, the capital expenditures of firm $i$ must be equal to the firm $i$ securities held by financial intermediaries and the central bank:

$$
Q k_{i}=S_{b, i}+S_{g, i}
$$

where $S_{b, i}$ denotes the representative financial intermediary's holdings of firm $i$ securities and $S_{g, i}$ denotes central bank holdings of firm $i$ securities.

A representative financial intermediary has exogenous financial wealth $N$ and along with investing in corporate securities invests in government bonds, $B$. The total supply of government bonds, $B^{S}$, is net positive, and clearing implies $B^{S}=$ $B_{b}+B_{g}$, where $B_{g}$ are central bank holdings of government bonds.

If the intermediary's holdings are not equal to its wealth, it either borrows or lends to households at gross interest rate $r$. The financial intermediary also faces a regulatory constraint limiting its leverage. This regulatory constraint will depend on the assets purchased and their concentration. ${ }^{11}$ We define our $J$ continuums of firms so that each continuum represents firms whose securities are treated identically in terms of capital requirements and concentration risk. In our model, the representative financial intermediary faces the following regulatory collateral constraint:

$$
V \geq \sum_{j} \theta \Delta_{j}\left(\int_{i \in j} S_{b, i} d i\right)^{\nu_{j}}+\theta
$$

where $\theta \Delta_{j}$ and $\theta$ are constants which reflect capital requirements for corporate bonds of firms $i \in j$ and government bonds (if holding government bonds is associated with lower capital requirements than holding corporate bonds, $\theta<\theta \Delta_{j}$ ). Parameters $\nu_{j} \geq 1$ reflect the penalty for concentration of assets of type $j .{ }^{12} V$ is the market value of the financial intermediary's equity. Note that with $\Delta_{j}=1 \forall j$ and no concentration risk and a representative intermediate good firm, this is similar to the collateral constraint in Gertler and Karadi (2013).

\footnotetext{
${ }^{11}$ This regulatory constraint is motivated by capital requirements placed on banks, which will differ for different asset classes, as well as the required bank stress testing, which penalizes high concentration of similar risky assets (due to greater exposure to common risk factors).

${ }^{12}$ If $\nu_{j}=1$, there is no penalty for concentration of securities of type $j$ firms.
} 
The financial intermediary maximizes its market value:

$$
V=\max _{S_{b, i}, B_{b}} \sum_{j} \int_{i \in j} S_{b, i} r_{i} d i+B_{b} r_{b}+\left(N-\sum_{j} \int_{i \in j} S_{b, i} d i-B_{b}\right) r
$$

subject to the collateral constraint (2).

Effect of LSAP on Bond Yields The maximization problem (3) yields the following first order condition for the interest rate on the debt of firm $i$ of type $j$ :

$$
\left(r_{i}-r\right)=\frac{\lambda}{(1+\lambda)} \theta \Delta_{j}\left(\int_{s \in j}\left(Q k_{s}-S_{g, s}\right) d s\right)^{\nu_{j}-1}
$$

where $\lambda$ is the Lagrangian multiplier on the collateral constraint. Note that since $S_{b, i}=Q k_{i}-S_{g, i}$, central bank purchases of corporate bonds enter this condition. A similar condition results for the interest rate on government bonds:

$$
\left(r_{b}-r\right)=\frac{\lambda}{(1+\lambda)} \theta
$$

However, purchases of government bonds $B_{g}$ only affect bond yields directly through their effect on the Lagrangian multiplier $\lambda$. Purchases of $B_{g}$ will reduce the financial intermediary's holdings of government bonds, $B_{b}=B^{S}-B_{g}$, and therefore loosen the collateral constraint, lowering $\lambda$ and yields. In contrast, purchases of corporate securities of firm $i$ of type $j$ will not only lower $\lambda$ through loosening the collateral constraint, but also lead to heterogeneous changes in spreads. This is due to the term $\left(\int_{s \in j}\left(Q k_{s}-S_{g, s}\right) d s\right)^{\nu_{j}-1}$ in (4). ${ }^{13}$

\subsubsection{Equilibrium}

Given exogenous bank net worth, $N$, firm-level productivities and wedges, $\left\{A_{i}, \tau_{i}^{k}\right\} \forall i$, and central bank purchases of corporate bonds, $\left\{S_{g, i}\right\} \forall i$, and government bonds, $B_{g}$, equilibrium in this model is a set of allocations $\left\{C, Y, K, B_{b}, B_{h}\right\}$,

\footnotetext{
${ }^{13}$ Naturally, firms will also endogenously respond to changing yields through their investment decisions in equilibrium, so $p_{i} k_{i}$ will change heterogeneously as well.
} 
and $\left\{k_{i}, y_{i}, S_{b, i}\right\} \forall i$ and prices $\left\{Q, r, r_{B}\right\}$ and $\left\{r_{i}, p_{i}\right\} \forall i$ such that households maximize consumption subject to their budget constraint; intermediate good firms, final good firms, and capital producers maximize profits; and financial intermediaries maximize profits subject to their collateral constraint; and clearing conditions hold.

\subsection{Effect of Central Bank Bond Buys}

In equilibrium, central bank purchases of government and corporate bonds will induce changes in bond yields and therefore firm decisions. The model does not admit an analytical solution for aggregates as a function of central bank bond purchases. ${ }^{14}$ Below, we show that we can however demonstrate analytically how firm and government spreads react to government bond purchases holding firm-capital choices fixed (the direct effect).

\subsubsection{Direct and Indirect Effects of Bond Buys}

Central bank purchases of either long-term government bonds $\left(B_{g}\right)$ or corporate securities of firm $i\left(S_{g, i}\right)$ will reduce the amount of that particular asset which have to be intermediated by the financial intermediary. Asset purchases will directly affect bond spreads in the following ways: 1) Change the Lagrangian multiplier on the collateral constraint, $\lambda$; 2) Change the first-order condition (4), by reducing the concentration of firms of type $j$ in the intermediary's balance sheet. Additionally, large-scale asset purchases will indirectly affect spreads through their effect on firm capital choices. Changing firm capital choices will also affect the price of capital, $Q$, and the amount of firm capital that needs to be intermediated, $Q k_{i}-S_{g, i}$, which enters directly into the collateral constraint.

The above statements can be codified by looking at the collateral constraint, which can be written as:

$$
\left(\sum_{j}\left(r_{j}-r\right) B_{j}\right)+B_{b}\left(r_{b}-r\right)+N * r \geq \sum_{j} \theta \Delta_{j} S_{b, j}^{\nu_{j}}+B_{b} \theta
$$

\footnotetext{
${ }^{14}$ This is due to the nonlinearity in the equation linking firm credit spreads to central bank bond purchases (due to firm-capital choices reacting to the change in spreads, a second-order effect).
} 
where $r_{j}$ is the spread on firms $i \in j$, which must be identical following (4), and $S_{b, j}=\int_{i \in j} S_{b, i} d i=\int_{i \in j}\left(Q k_{i}-S_{g, i}\right) d i$. Purchases of corporate securities, $S_{b, i}$, or long-term government bonds, $B_{b}$, lower the amount the financial intermediary has to intermediate (right-hand side of the collateral constraint). Proposition 1 formalizes the effect of LSAPs on bond spreads holding firm-capital choices fixed:

Proposition 1. Holding firm capital choices, $k_{i}$, fixed, central bank LSAPs have the following effects:

(i) A purchase of long-term government bonds, $B_{g}$

(a) Decreases $\lambda$, the Lagrangian multiplier on the collateral constraint

(b) Proportionately decreases firm spreads, i.e. $\frac{\Delta\left(r_{i}-r\right)}{\left(r_{i}-r\right)}$ is constant for all firms.

(ii) A purchase of firm securities, $S_{g, i}$ for $i \in j$

(a) Decreases $\lambda$, the Lagrangian multiplier on the collateral constraint, if $N * r \geq \frac{\left(\nu_{j}-1\right)}{\nu_{j}} B_{b} \theta+\left(\sum_{s} \int_{i \in s}\left(1-\frac{\nu_{s}}{\nu_{j}}\right) \theta_{s} S_{b, i}^{\nu_{s}}\right)$ where $s \neq j$.

(b) Does not lead to a proportionate decrease in firm spreads, i.e. $\frac{\Delta\left(r_{i}-r\right)}{\left(r_{i}-r\right)}$ is greater for firms of type $i \in * j$ than other types whose debt is not purchased $(i \notin j)$.

Proof. See Appendix A.

This proposition formalizes the key effects of LSAPs on spreads. Directly buying the securities of only firms of type $i \in j$ will, holding capital choices constant, lower their spreads by more than firms with $i \notin j$. This can be contrasted with the effect of purchases of long-term government debt, which will lower spreads proportionately. However, both purchases of long-term government bonds and corporate securities will, under some reasonable conditions, decrease spreads by loosening the collateral constraint faced by financial intermediaries (implying a lower multiplier on the constraint, $\lambda) .{ }^{15}$

\footnotetext{
${ }^{15}$ Holding capital decisions fixed, this is always true for purchases of government debt. For purchases of corporate securities, the condition in Proposition 1 (ii)(a) must hold, which can be understood as implying that firms must not hold too much government debt relative to wealth, with an adjustment for heterogeneous $\nu_{j}$.
} 
Therefore, central bank LSAPs of corporate securities will induce asymmetric changes in spreads and therefore firm cost of capital. Through the first-order condition for capital, (7), these spreads will induce changes in firm capital choices and therefore both the allocation of capital and aggregate capital supply. Subsection 2.2.2 demonstrates how such differences in spreads map into a misallocation of resources.

\subsubsection{Allocative Efficiency}

Proposition 1 tells us how government and corporate bond buys directly affect borrowing rates of firms and the government, holding fixed the indirect effect of firm decisions changing in response. Although we cannot directly map bond buys to aggregates analytically, to develop intuition as to how bond buys affect allocative efficiency, it is useful to walk through how spreads affect the allocation and aggregates. In equilibrium, we can express the relative holdings of firm capital as:

$$
\frac{k_{i}}{K}=\frac{\left(\frac{A_{i}^{\rho}}{r_{i} \tau_{i}^{k}}\right)^{\frac{1}{1-\gamma-\alpha \rho}}}{\sum_{j} \int_{i \in j}\left(\frac{A_{i}^{\rho}}{r_{i} \tau_{i}^{k}}\right)^{\frac{1}{1-\gamma-\alpha \rho}} d i} .
$$

Therefore, the relative levels of firm cost-of-capital, $r_{i}$, have implications for the relative allocation of capital. Additionally, firm cost-of-capital affects the aggregate demand for capital:

$$
K=\frac{\left(\int\left(\frac{A_{i}^{\rho}}{\left(r_{i} \tau_{i}^{k}\right)^{\alpha \rho}}\right)^{\frac{1}{1-\alpha \rho}} d i\right)^{\frac{1-\rho}{\rho\left(1-\alpha+b_{k}\right)}}\left(\int\left(\frac{A_{i}^{\rho}}{\left(r_{i} \tau_{i}^{k}\right)}\right)^{\frac{1}{1-\alpha \rho}} d i\right)^{\frac{1-\alpha}{1-\alpha+b_{k}}}}{\left(\frac{h_{k}}{\alpha \rho}\right)^{\frac{1}{1-\alpha+b_{k}}}} .
$$

In equilibrium, our model yields macroeconomic aggregates as an analytical function of firm interest rates, $r_{i}$, and exogenous variables $\left(A_{i}, \tau_{i}^{k} \forall i\right)$. Building on (7), we can express aggregate output as: 


$$
Y=\underbrace{K^{\alpha}}_{\text {Capital }} \underbrace{\frac{\left(\int\left(\frac{A_{i}^{\rho}}{\left(r_{i} \tau_{i}^{k}\right)^{\alpha \rho}}\right)^{\frac{1}{1-\alpha \rho}} d i\right)^{\frac{1}{\rho}}}{\left(\int\left(\frac{A_{i}^{\rho}}{r_{i} \tau_{i}^{k}}\right)^{\frac{1}{1-\alpha \rho}} d i\right)^{\alpha}} .}_{\text {Allocation }}
$$

Note that (8) shows that output can be expressed as a function of aggregate capital, $K^{\alpha}$, modified by a term which captures both the productivity of intermediate good firm production functions and the efficiency of the allocation of capital. For example, if there is no heterogeneity $\left(A_{i}=A, r_{i}=r_{A}, \tau_{i}^{k}=\tau^{k}\right)$, then (8) reduces to $Y=A K^{\alpha}$.

To more clearly demonstrate the effect of spreads on output and allocative efficiency, we define $r_{A}$, the weighted-average interest rate faced by firms. It is defined such that aggregate capital depends only on $r_{A}$ (and does not depend on heterogeneity in interest rates):

$$
\frac{1}{r_{A}}=\frac{\left(\int\left(\frac{A_{i}^{\rho}}{\left(\tau_{i}^{k}\right)^{\alpha \rho}}\right)^{\frac{1}{1-\alpha \rho}}\left(\frac{1}{r_{i}}\right)^{\frac{\alpha \rho}{1-\alpha \rho}} d i\right)^{\frac{1-\rho}{\rho}}\left(\int\left(\frac{A_{i}^{\rho}}{\tau_{i}^{k}}\right)^{\frac{1}{1-\alpha \rho}}\left(\frac{1}{r_{i}}\right)^{\frac{1}{1-\alpha \rho}} d i\right)^{1-\alpha}}{\left(\int\left(\frac{A_{i}^{\rho}}{\left(\tau_{i}^{k}\right)^{\alpha \rho}}\right)^{\frac{1}{1-\alpha \rho}} d i\right)^{\frac{1-\rho}{\rho}}\left(\int\left(\frac{A_{i}^{\rho}}{\left(\tau_{i}^{k}\right)}\right)^{\frac{1}{1-\alpha \rho}} d i\right)^{1-\alpha}} .
$$

Note that if all firms have the same interest rate, $r_{i}=r_{A}$. We then define interest rate wedges, $r_{\tau, i}$, between firm interest rates and the weighted-average firm interest rate:

$$
r_{\tau, i}=\frac{r_{A}}{r_{i}}
$$

These expressions allow us to derive an expression for output, as a function of aggregate capital, which depends only on the weighted-average interest rate $r_{A}$, and on productivity and allocative efficiency, which depends only on firm productivities 
$A_{i}$, interest rate wedges $r_{\tau, i}$, and other exogenous distortions $\tau_{i}^{k}$ :

$$
Y=\underbrace{K^{\alpha}}_{\text {Capital }} \underbrace{\left(\int\left(\frac{A_{i}^{\rho}}{\left(\tau_{i}^{k}\right)^{\alpha \rho}}\right)^{\frac{1}{1-\alpha \rho}} d i\right)^{\frac{(1-\rho) \alpha}{\rho(1-\alpha)}}\left(\int\left(\frac{A_{i}^{\rho}}{\left(\tau_{i}^{k}\right)}\right)^{\frac{1}{1-\alpha \rho}} d i\right)^{\alpha}}_{\text {Allocation }} .
$$

From (9), and building on proposition 1, there are two first-order consequences of central bank purchases of corporate securities that lower bond spreads heterogeneously. First, they will lower the weighted-average interest rate, $r_{A}$, leading to greater aggregate investment and capital. However, they can also generate interest rate wedges, $r_{\tau, i}$, which have consequences for the allocation of capital relative to the efficient level. The size (and direction) of these effects depend on how far the baseline allocation is from its efficient level and whether the interest rate wedge changes induced by bond buys exacerbates or undoes distortions. The latter point can be further formalized by deriving output-maximizing interest rate wedges, as we do in the proposition below.

Proposition 2. The output-maximizing allocation of firm interest rate wedges satisfies $r_{\tau, i}^{*} \propto \tau_{i}^{k}$

Equivalently, $r_{\tau, i}^{*} \propto r_{A} \frac{1}{\tau_{i}^{k}}$

Proof. See Appendix A.

Proposition 2 shows that the optimal interest rate wedges are such that they exactly offset exogenous distortions $\tau_{i}^{k}$. If there are no exogenous distortions, then the optimal allocation arises when firms all have identical cost of capital $r_{A}=r_{i}$. Thus, given large-scale corporate bond buy can induce heterogeneous movements in spreads, it can cause (reverse) a misallocation by moving interest rate wedges away from (towards) the efficient allocation. 


\section{New-Keynesian DSGE Model}

We evaluate the impact of the misallocative effect of large-scale bond purchases in a richer environment where the effect of central bank asset purchases on firm borrowing rates are endogenized. Along with explicitly modeling banks, the Gertler and Karadi (2013) model has the key elements of a New-Keynesian model: Households, nonfinancial firms, capital goods producers, retail good firms, a Central Bank, and a government. It is useful to start by outlining the changes we make to the nonfinancial firm sector and to then discuss the changes made to the household and banking sectors. Afterwards, we outline the remainder of the model and define an equilibrium. To keep the text self-contained, we outline the full model even though aspects of the model such as the retail good firm's problem will remain exactly as in Gertler and Karadi (2013). Throughout, we emphasize how introducing heterogeneity implies changes to the model of Gertler and Karadi (2013).

\subsection{Model Description}

Nonfinancial and capital good firms Nonfinancial intermediate good firms are one of two types $j \in(1,2)$ with production technology:

$$
Y_{j, t}=A_{t} K_{j, t}^{\alpha \varsigma} L_{j, t}^{(1-\alpha) \varsigma}
$$

where $Y_{j, t}$ is intermediate good output of type $j$ firms, $K_{j, t}$ is the type $j$ firm capital stock, $L_{j, t}$ is the type $j$ total employment, $\alpha \in(0,1)$ governs capital's share in production, and $\varsigma \in(0,1]$ is the degree of returns to scale. Total intermediate good firm output, $Y_{m, t}$ is then:

$$
Y_{m, t}=\sum_{j} \omega_{j} Y_{j, t}
$$

where $\omega_{j}$ is a parameter greater than or equal to 0 that is a factor affecting the extent to which intermediate good firm $j^{\prime} s$ output enters total output. Thus, $\sum_{j} \omega_{j}$ is potentially greater than 1 .

Define $P_{m, t}$ as the relative price of intermediate goods. Also, $W_{t}$ is the wage 
rate shared across firms. Then we can recover firm $j$ 's demand for labor from:

$$
W_{t}=P_{m, t} \frac{Y_{j, t}}{L_{j, t}} \omega_{j}(1-\alpha),
$$

which holds for each type $j$. Also, gross profits per unit of capital for firm $j, Z_{j, t}$, becomes:

$$
Z_{j, t}=\omega_{j}(1-(1-\alpha) \varsigma) \frac{P_{m, t} Y_{j, t}}{\xi_{t} K_{j, t-1}}
$$

where $\xi_{t}$ is the capital quality shock, and this equation holds for each type $j .{ }^{16}$ We assume that capital is transferable between firms, and thus have the capital accumulation equation:

$$
K_{t+1}=\xi_{t+1}\left[I_{t}+(1-\delta) K_{t}\right]
$$

Overall, the problem of the intermediate good firms differs from Gertler and Karadi (2013), in that there are now two types of firms rather than one. We also introduce a parameter $\varsigma$, which controls how costly a misallocation of inputs is for aggregate output. Thus, our definitions of intermediate good firm demand for labor and gross profits per unit of capital for the firm also differ.

The capital good producer solves the following maximization problem:

$$
\max E_{t} \sum_{t=\tau}^{\infty} \Lambda_{t, \tau}\left\{Q_{\tau} I_{\tau}-\left[1+f\left(\frac{I_{\tau}}{I_{\tau-1}}\right)\right] I_{\tau}\right\}
$$

where $\Lambda_{t}$ is a discount factor that will be obtained from the household's problem, in equilibrium.

Thus, the price of capital goods can be determined from profit maximization as:

$$
Q_{t}=1+f\left(\frac{I_{t}}{I_{t-1}}\right)+\frac{I_{t}}{I_{t-1}} f^{\prime}\left(\frac{I_{t}}{I_{t-1}}\right)-E_{t} \Lambda_{t, t+1}\left(\frac{I_{t+1}}{I_{t}}\right)^{2} f^{\prime}\left(\frac{I_{t+1}}{I_{t}}\right)
$$

\footnotetext{
${ }^{16}$ In this setup, capital owners receive firm income less wages paid, which is equal to the marginal product of capital if firms produce with constant returns to scale $(\varsigma=1)$.
} 
Imposing the functional form for $f$ considered in Gertler and Karadi (2013) in (11), we get:

$$
Q_{t}=1+\frac{\eta_{i}}{2}\left(\frac{I_{t}}{I_{t-1}}-1\right)^{2}+\eta_{i}\left(\frac{I_{t}}{I_{t-1}}-1\right) \frac{I_{t}}{I_{t-1}}-E_{t} \Lambda_{t, t+1}\left(\frac{I_{t+1}}{I_{t}}\right)^{2} \eta_{i}\left(\frac{I_{t+1}}{I_{t}}-1\right),
$$

where $\eta_{i}$ is the inverse elasticity of net investment to the price of capital.

Firms require financing of their capital stocks, and they do so by issuing statecontingent claims that are perfectly monitored and enforced and thus perfectly statecontingent. If $\xi_{t+1}$ is the capital quality shock, the period $t+1$ payoff of the security of firm $j$ is $\left(Z_{j, t+1}+(1-\delta) Q_{t+1}\right) \xi_{t+1}$. Thus, the security of firm $j$ has a rate of return of:

$$
R_{k, j, t+1}=\frac{Z_{j, t+1}+(1-\delta) Q_{t+1}}{Q_{t}} \xi_{t+1}
$$

The rate of return therefore has a relationship with $Z_{j, t}$, profits per unit of capital, which depends on $K_{j, t}$. Since $Q_{t}$ is common to the two types of firms, difference in the rates of return, $R_{k, j, t+1}$, imply differences in per-capital profit rates and allocation of capital between the two types.

Retail Good Firm Problem The final good, $Y_{t}$, is produced using a mass one continuum of differentiated retail goods using CES production:

$$
Y_{t}=\left[\int_{0}^{1} Y_{f t}^{\frac{\epsilon-1}{\epsilon}} d f\right]^{\frac{\epsilon}{\epsilon-1}}
$$

Retail good firms, however, just take intermediate output and repackage it. Thus, the marginal cost of production is $P_{m t}$, the price of the output of intermediate good firms. The retail good firm faces Calvo pricing. It can adjust its price with probability $1-\gamma$. The firms choose the same reset price $P_{t}^{*}$. Following the usual arguments, we can obtain the first-order condition:

$$
\sum_{i=0}^{\infty} \gamma^{i} \Lambda_{t, t+i}\left[\frac{P_{t}^{*}}{P_{t+i}}-\mu P_{m t+i}\right] Y_{f t+i}=0
$$


with $\mu=\frac{1}{1-1 / \epsilon}$. We can thus recover the law of motion for prices:

$$
P_{t}=\left[(1-\gamma)\left(P_{t}^{*}\right)+\gamma\left(P_{t-1}^{1-\epsilon}\right)\right]^{\frac{1}{1-\epsilon}}
$$

Households As in Gertler and Karadi (2013), there is a measure one continuum of households (all identical), each of whom consumes the final good, saves by lending funds to banks and potentially the Central Bank and supplies labor. ${ }^{17}$

Each household is composed of a fraction $1-f$ workers and $f$ bankers, and has perfect consumption insurance. Workers are the members which supply labor to earn real wage, $W_{t}$, which the household shares among itself. Bankers manage specific banks and also shares any earnings with the household as a whole. In effect, the household owns the bank that its bankers manage. Define the overall earnings from working and non-financial and financial firms as $\Pi_{t}$. Households pay taxes, $T_{t}$. The household deposits funds in banks, but only in banks the household's bankers do not manage. Workers can become bankers and vice-versa over time. With probability $\sigma$, bankers stay bankers, and with probability $1-\sigma$, bankers become workers. Bankers face a finite horizon problem; in effect, they cannot retain earnings beyond the point which they can fund all investment from their own capital. Workers randomly are selected to replace the bankers who switch to workers, and receive a startup fund of $\frac{X}{(1-\sigma) f}$.

The household consumes $C_{t}$ units of the final good. $L_{t}$ is family labor supply. The household has habits in consumption, and the household's utility, $u_{t}$, is defined as follows:

$$
u_{t}=E_{t} \sum_{t}^{\infty} \beta^{i}\left[\ln \left(C_{t+i}-h C_{t+i-1}\right)-\frac{\chi}{1+\varphi} L_{t+1+i}^{1+\varphi}\right]
$$

where $0<\beta<1,0<h<1$, and $\chi, \phi>0$.

Households are indifferent between deposits and government debt, as they both pay rate of return between periods $t-1$ and $t$ of $R_{t}$, in equilibrium. Thus, we make this assumption throughout, calling both short-term debt, $D_{h, t}$. We can thus define

\footnotetext{
${ }^{17}$ The economy we consider is the cashless limit.
} 
the household's budget constraint to be:

$$
C_{t}=W_{t} L_{t}+\Pi_{t}-X+T_{t}+R_{t} D_{h, t-1}-D_{h, t}
$$

The household thus solves (13) subject to (14) choosing $C_{t}, L_{t}$, and $D_{h t}$. Define $u_{C t}$ to be the marginal utility of consumption. We then have labor supply condition:

$$
u_{C t} W_{t}=\chi L_{t}^{\varphi}
$$

and consumption-savings optimality condition:

$$
E_{t} \beta \frac{u_{C, t+1}}{u_{C, t}} R_{t+1}=1
$$

It is also useful to define:

$$
\Lambda_{t, t+1}=E_{t} \beta \frac{u_{C, t+1}}{u_{C, t}}
$$

as it is the discount factor of firms and intermediaries.

Holding Costs A useful extension of the model is to allow households to directly hold securities in the face of holding costs. Define $S_{h, j, t}$ as the securities of firm $j$ held by the household at time $t$ and $B_{h, j, t}$ as securities of the government held by the household at time $t$ with price $q_{t}$. Holdings costs for type $j$ firm securities are $\frac{\kappa_{j}}{2} \frac{\left(S_{h, j}-S_{h, j}^{-}\right)^{2}}{S_{h, j}}$ where parameters $\kappa_{j}$ and $\overline{S_{h, j}^{-}}$are positive and $S_{h, j} \geq \overline{S_{h, j}^{-}}$. Holding costs for government securities are: $\frac{\kappa_{j}}{2} \frac{\left(B_{h}-\bar{B}_{h}\right)^{2}}{B_{h}}$, where parameters $\kappa_{j}$ and $\bar{B}_{h}$ are positive and $B_{h} \geq \bar{B}_{h}$.

With holding costs, we rewrite budget constraint of the household:

$$
\begin{array}{r}
C_{t}+D_{h t}+\sum_{j=1}^{j=2} Q_{j, t}\left(S_{h, j, t}+\frac{1}{2} \kappa\left(S_{h, j, t}-S_{h, j}\right)^{2}\right)+q_{t}\left(B_{h, t}+\frac{1}{2} \kappa\left(B_{h, t}-\overline{B_{h}}\right)^{2}\right) \\
=W_{t} L_{t}+\Pi_{t}+T_{t}-X+R_{t} D_{h, t-1}+\sum_{j=1}^{j=2} R_{k, j, t} S_{h, j, t-1}+R_{b, t} B_{h, t-1},
\end{array}
$$


where $R_{b, t}$ is the return on government bonds.

Banks The problem of banks differs from Gertler and Karadi (2013), in that it accounts for the additional heterogeneity in available securities and there is now the regulatory constraint that favors government bonds relative to type 1 firm securities and type 1 securities relative to type 2 firm securities.

Banks make long-term loans to nonfinancial firms and the government, which are funded by their liabilities (short-term deposits of households). The rate of return on a loan will be equal to the return on the security defined in (12). There are government bonds, $b_{t}$, that are available to households and banks, which are perpetuities and pay one dollar per period. If $q_{t}$ is the price of the bond and $P_{t}$ is the price level, the real rate of return on the bond $R_{b, t+1}$ is:

$$
R_{b, t+1}=\frac{\frac{1}{P_{t}}+q_{t+1}}{q_{t}}
$$

The balance sheet of a bank is:

$$
Q_{1, t} s_{1, t}+Q_{2, t} s_{2, t}+q_{t} b_{t}=n_{t}+d_{t}
$$

where $n_{t}$ is bank net worth, $d_{t}$ are deposits held, $s_{j, t}$ for $j \in\{1,2\}$ are the securities holdings by the bank of firm's 1 and 2 respectively. Net worth is the difference between the gross return on assets and the cost of deposits:

$$
n_{t}=R_{k, 1, t} Q_{t-1} s_{1, t-1}+R_{k, 2, t} Q_{t-1} s_{2, t-1}+R_{b, t} q_{t-1} b_{t-1}-R_{t} d_{t-1} .
$$

The banker will maximize its expected discounted value of net worth:

$$
V_{t}=E_{t} \sum_{i=1}^{\infty}(1-\sigma) \sigma^{i-1} \Lambda_{t, t+1} n_{t+1}
$$

Banks face an incentive constraint due to an imperfect monitoring problem of the bank by depositors wherein the government regulations on asset holdings also enter:

$$
V_{t} \geq \theta Q_{t} s_{1, t}^{\nu_{s, 1}}+\theta \Delta_{s} Q_{t} s_{2, t}^{\nu_{s, 2}}+\Delta \theta q_{t} b_{t}^{\nu_{b}}
$$


where $\nu_{s, 1}, \nu_{s, 2}$, and $\nu_{b}$ are parameters all greater than or equal to one and govern the extent to which it is costly to hold a given asset $s_{1, t}, s_{2, t}$, and $b_{t}$, respectively. ${ }^{18}$ Also, parameters $\theta, \theta \Delta_{s}$, and $\theta \Delta$ are the respective amounts of banker's portfolios of $s_{1, t}, s_{2, t}$, and $b_{t}$, the bank can divert, where $0 \geq\left\{\Delta, \Delta_{s}\right\}$. This constraint can also be interpreted as a collateral/regulatory constraint, where $\theta$ and $\left\{\Delta, \Delta_{s}\right\}$ are parameters that govern how tightly the collateral constraint binds on different assets, while $\nu_{s, 1}, \nu_{s, 2}$, and $\nu_{b}$ act as either holding costs or tighter regulatory constraints due to concentration in particular asset classes.

Bankers choose $s_{1, t}, s_{2, t}$, and $b_{t}$ to maximize (18) subject to (16), (17), and (19). We describe the solution to this problem below.

Solution to Banker's Problem If bankers choose $s_{1, t}, s_{2, t}$, and $b_{t}$ to maximize (18) subject to (16), (17), and (19), the Lagrangian is:

$$
\begin{aligned}
\mathcal{L}= & E_{t}\left[\Lambda_{t, t+1}\left((1-\sigma) n_{t+1}+\sigma V_{t+1}\right)\right]+\lambda_{t}\left(E_{t}\left[\Lambda_{t, t+1}\left((1-\sigma) n_{t+1}+\sigma V_{t+1}\right)\right]\right. \\
& \left.-\theta Q_{t} s_{t}^{\nu_{s, 1}}-\theta \Delta_{s} Q_{t} s_{t}^{\nu_{s, 2}}-\Delta \theta q_{t} b_{t}^{\nu_{b}}\right),
\end{aligned}
$$

where

$$
\begin{aligned}
n_{t}= & R_{k, 1, t} Q_{1, t-1} s_{1, t-1}+R_{k, 2, t} Q_{2, t-1} s_{2, t-1}+ \\
& R_{b, t} q_{t-1} b_{t-1}-R_{t}\left(Q_{1, t-1} s_{1, t-1}+Q_{2, t-1} s_{2, t-1}+q_{t-1} b_{t-1}-n_{t-1}\right) .
\end{aligned}
$$

Let $\lambda_{t}$ be the Lagrange multiplier associated with the incentive constraint (19).

The first-order conditions here yield:

$E_{t}\left[\Lambda_{t, t+1}\left((1-\sigma)+\sigma \frac{\partial V_{t+1}}{\partial n_{t+1}}\right)\left(R_{k, 1, t+1}-R_{t+1}\right)\right]=\frac{\lambda_{t}}{\left(1+\lambda_{t}\right)} \theta \nu_{s, 1} s_{1, t}^{\nu_{s, 1}-1}$,

\footnotetext{
${ }^{18}$ We justify this modeling choice through the stress tests that banks have to pass - if they concentrate their holdings narrowly, they may be forced to maintain more capital.
} 
$E_{t}\left[\Lambda_{t, t+1}\left((1-\sigma)+\sigma \frac{\partial V_{t+1}}{\partial n_{t+1}}\right)\left(R_{k, 2, t+1}-R_{t+1}\right)\right]=\frac{\lambda_{t}}{\left(1+\lambda_{t}\right)} \Delta_{s} \theta \nu_{s, 2} s_{2, t}^{\nu_{s, 2}-1}$

and

$$
E_{t}\left[\Lambda_{t, t+1}\left((1-\sigma)+\sigma \frac{\partial V_{t+1}}{\partial n_{t+1}}\right)\left(R_{b, t+1}-R_{t+1}\right)\right]=\frac{\lambda_{t}}{\left(1+\lambda_{t}\right)} \Delta \theta \nu_{b} b_{t}^{\nu_{b}-1}
$$

noting that

$$
\frac{\partial V_{t}}{\partial n_{t}}=E_{t} \tilde{\Lambda}_{t, t+1}\left(\left(R_{k, t+1}-R_{t+1}\right) \phi_{t}+R_{t+1}\right)
$$

where

$$
\phi_{t}=\frac{E_{t}\left[\tilde{\Lambda}_{t, t+1} R_{t+1}\right]}{\theta \nu_{s, 1} s_{1, t}^{\nu_{s, 1}-1}-E_{t}\left[\tilde{\Lambda}_{t, t+1}\left(R_{k, 1, t+1}-R_{t+1}\right)\right]} .
$$

Let $\tilde{\Lambda}_{t, t+1}$ be the bank's augmented stochastic discount factor, equal to the product of $\Lambda_{t, t+i}$, i.e. the discount factor from the household's problem as defined in (15), and the multiplier $\left((1-\sigma)+\sigma \frac{\partial V_{t+1}}{\partial n_{t+1}}\right)$.

Thus, we have the following arbitrage conditions:

$$
E_{t}\left[\tilde{\Lambda}_{t, t+1}\left(R_{b, t+1}-R_{t+1}\right)\right]=\Delta \frac{\nu_{b} b_{t}^{\nu_{b}-1}}{\nu_{s, 1} s_{t, 1}^{\nu_{s, 1}-1}} E_{t}\left[\tilde{\Lambda}_{t, t+1}\left(R_{k, 1, t+1}-R_{t+1}\right)\right]
$$

and

$$
E_{t}\left[\tilde{\Lambda}_{t, t+1}\left(R_{k, 2, t+1}-R_{t+1}\right)\right]=\Delta_{s} \frac{\nu_{s, 2} s_{2, t}^{\nu_{s, 2}-1}}{\nu_{s, 1} s_{t, 1}^{\nu_{s, 1}-1}} E_{t}\left[\tilde{\Lambda}_{t, t+1}\left(R_{k, 1, t+1}-R_{t+1}\right)\right]
$$


Aggregation If we integrate (20) and plug the solution into (19), we obtain the following leverage restriction:

$$
n_{t} \phi_{t} \geq \frac{Q_{1, t} s_{1, t}}{\nu_{s, 1}}+\Delta_{s} Q_{2, t} \frac{s_{2, t}^{\nu_{s, 2}}}{\nu_{s, 1} s_{1, t}^{\nu_{s, 1}-1}}+\Delta q_{t} \frac{b_{t}^{\nu_{b}}}{\nu_{s, 1} s_{1, t}^{\nu_{s, 1}-1}}
$$

which is an inequality when $\lambda_{t}=0$, and binds when $\lambda_{t}>0$.

Across banks, we thus have the leverage restriction:

$$
N_{t} \phi_{t} \geq \frac{Q_{1, t} S_{b, 1, t}}{\nu_{s, 1}}+\Delta_{s} Q_{2, t} \frac{S_{b, 2, t}^{\nu_{s, 2}}}{\nu_{s, 1} S_{b, 1, t}^{\alpha_{s}-1}}+\Delta q_{t} \frac{B_{b, t}^{\nu_{b}}}{\nu_{s, 1} S_{b, 1, t}^{\nu_{s, 1}-1}}
$$

where $N_{t}$ is aggregate bank net worth, and $B_{b, t}$ is total bank holdings of government bonds. We can also derive the law of motion for total net worth of the banking sector as:

$N_{t}=\sigma\left(\sum_{j=1}^{j=2}\left(\left(R_{k, j, t}-R_{t}\right) \frac{Q_{j, t-1} S_{b, j, t-1}}{N_{t-1}}\right)+\left(R_{b, t}-R_{t}\right) \frac{q_{t-1} B_{b, t-1}}{N_{t-1}}\right) N_{t-1}+N_{e}$

where $N_{e}$ is the wealth of entering bankers.

Central Bank and Government Policy The Central Bank (CB) acts as in Gertler and Karadi (2013), in that it can purchase either government bonds (short or long term) or private securities. We only allow the Central Bank to purchase the securities of type 1 (large) firms, however.

The CB can issue riskless short-term debt $D_{g, t}$ which pay $R_{t+1} \cdot{ }^{19}$ Thus, the CB has balance sheet:

$$
Q_{1, t} S_{g, 1, t}+q_{t} B_{g, t}=D_{g, t}
$$

\footnotetext{
${ }^{19}$ See Gertler and Karadi (2013) for a discussion of the different intepretations of the short-term debt issued by the household and the CB.
} 
where $S_{g, 1, t}$ is CB holdings of type 1 securities, and $B_{g, t}$ is CB holdings of government bonds. ${ }^{20}$ The $\mathrm{CB}$ costlessly transfers any profits to or recovers any losses from Treasury. Following Gertler and Karadi (2013), we assume the CB is less efficient in intermediation than banks and thus pays $\tau_{s, j}$ per unit of type $j$ bonds intermediated and $\tau_{b}$ per unit of government bonds.

The CB determines monetary policy using a Taylor rule. Define $i_{t}$ as the net nominal interest rate, $i$ as the steady-state nominal rate, $\pi_{t}$ as the inflation rate $P_{t+1} / P_{t}$, and $Y_{t}^{*}$ as the flexible-price equilibrium level of output. Then:

$$
i_{t}=i+\kappa_{\pi} \pi_{t}+\kappa_{y}\left(\log \left(Y_{t}\right)-\log \left(Y_{t}^{*}\right)\right)+\epsilon_{t}
$$

where $\epsilon_{t}$ is an exogenous shock. When we allow for a zero-lower bound on interest rates:

$$
i_{t}=\max \left\{0, i+\kappa_{\pi} \pi_{t}+\kappa_{y}\left(\log \left(Y_{t}\right)-\log \left(Y_{t}^{*}\right)\right)+\epsilon_{t}\right\} .
$$

We can then determine the real interest rate with the standard Fisher relation:

$$
1+i_{t}=R_{t+1} \frac{P_{t+1}}{P_{t}}
$$

Clearing for each type $j$ securities implies:

$$
S_{j, t}=S_{b, j, t}+S_{h, j, t}+S_{g, j, t},
$$

where $S_{j, t}$ is total holdings of type $j$ securities.

Also, we have clearing for government bonds, which implies:

$$
B_{t}=B_{b, t}+B_{h, t}+B_{g, t},
$$

where $B_{b, t}$ is bank holdings of government bonds.

Combining (21) with our securities clearing conditions above, we can obtain an

\footnotetext{
${ }^{20} S_{g, 2, t}$ or CB holdings of type 2 assets is restricted to be zero and thus does we do not write it into the constraint.
} 
aggregate balance sheet constraint:

$$
\begin{aligned}
N_{t} \phi_{t} & \geq \frac{Q_{1, t}\left(S_{1, t}-S_{h, 1, t}-K_{g, 1, t}\right)}{\nu_{s, 1}}+\Delta_{s} Q_{2, t} \frac{\left(S_{2, t}-S_{h, 2, t}\right)^{\nu_{s, 2}}}{\nu_{s, 1} S_{1, t}^{\alpha_{s}-1}} \\
& +\Delta q_{t} \frac{\left(B_{t}-B_{h, t}-B_{g, t}\right)^{\nu_{b}}}{\nu_{s, 1} S_{1, t}^{\nu_{s, 1}-1}}
\end{aligned}
$$

which determines total demand for securities net of household holdings. Holding costs of the household thus matter. By type $j$, as $\kappa_{j}$ goes to zero, Central Bank asset purchases become less effective, and as holding costs rise, they become more effective.

As in Gertler and Karadi (2013), government consumption, $G$, and the net interest payments from fixed amount of long-term bonds $\bar{B}$. Revenues will include $\mathrm{CB}$ earnings net costs plus collected taxes.

We thus have the consolidated government budget constraint:

$$
\begin{aligned}
G+\left(R_{b t}-1\right) \bar{B}= & T_{t}+\sum_{j=1}^{j=2}\left(R_{k, j, t}-R_{t}-\tau_{s, j}\right) Q_{j, t-1} S_{g, j, t-1}+ \\
& \left(R_{b, t}-R_{t}-\tau_{b}\right) q_{t-1} B_{g, t-1} .
\end{aligned}
$$

Also, notice that clearing for long-term government bonds will be fixed by the government such that $B_{t}=\bar{B}$.

The government LSAP policy is a function of first-order stochastic processes, $\varphi_{s, 1, t}, \varphi_{s, 2, t}$, and $\varphi_{b, t}$, such that:

$$
\begin{aligned}
S_{g, 1, t} & =\varphi_{s, 1, t} S_{g, 1, t-1} \\
B_{g, t} & =\varphi_{b, t} B_{g, t-1} .
\end{aligned}
$$

When $\Delta_{s}>1$, limits to arbitrage are weaker for private securities of type 2 than private securities of type 1 firms. Thus, all else equal, if there is an asset purchase, private securities of type 1 should move by more than private securities of type 2 . A similar result is true for government bonds when $\Delta<1$. Further, $\nu_{s, 1}$ and $\nu_{s, 2}$, when greater than one, affect the desired stock of holdings, further altering the extent to 
which excess returns adjust after a bond purchase.

Resource Constraint, Further Clearing Conditions, and Equilibrium The equilibrium conditions of the model are similar to Gertler and Karadi (2013), except now we have two equations for clearing in both types of capital and we adjust for the two types of labor in the single labor market clearing condition.

We have the resource constraint:

$$
Y_{t}=C_{t}+\left[1+f\left(\frac{I_{t}}{I_{t-1}}\right)\right] I_{t}+G+\tau_{s} Q_{t-1} S_{g, t-1}+\tau_{g} q_{t-1} B_{g, t-1}
$$

We then require supply equals demand in our different markets. In our market for labor:

$$
\omega_{1}(1-\alpha) \varsigma \frac{Y_{1, t}}{L_{1, t}} \frac{Y_{t}}{Y_{m, t}} E_{t} u_{C, t}=\frac{1}{P_{m, t}} \chi L_{t}^{\phi},
$$

and

$$
\omega_{2}(1-\alpha) \frac{Y_{2, t}}{L_{2, t}} \frac{Y_{t}}{Y_{m, t}} E_{t} u_{C, t}=\frac{1}{P_{m, t}} \chi L_{t}^{\phi}
$$

where $L_{t}=L_{1, t}+L_{2, t}$.

In the market for capital, we have:

$$
S_{1, t}+S_{2, t}=I_{t}+(1-\delta) K_{t}
$$

where $K_{t}=K_{1, t}+K_{2, t}$.

Notice, with clearing in the markets for goods, labor, and all securities, by Walras' Law the market for riskless short-term debt also clears.

\subsection{Misallocation}

We can construct a measure of misallocation by first constructing a counterfactual measure of output: the maximum output, $\hat{Y}$, which can be produced with a fixed 
amount of labor and capital. In our production environment, $\hat{Y}$ can be expressed as:

$$
\hat{Y}_{t}=A_{t} K_{t}^{\alpha \varsigma} L_{t}^{(1-\alpha) \varsigma}\left(\sum_{j=1}^{j=2} \omega_{j}^{\frac{1}{1-\varsigma}}\right)^{1-\varsigma} .
$$

We therefore can define the losses from misallocation as $\hat{Y}_{t}-Y_{t}$.

\subsection{Calibration}

We present the parameters used in our quantitative exercise in Table 1. In our calibration exercise, we hold fixed the parameters from Gertler and Karadi (2013) and calibrate the new parameters we introduced.

For the regulatory constraint parameters, we motivate the calibration with the following two points: 1) It is generally less costly for a bank to hold government debt than corporate debt due to differences in liquidity in these assets. 2) Government debt is considered Level 1 capital as a High Quality Liquid Asset (HQLA) in computing the Liquidity Coverage Ratio for Basel III, while non-bank investmentgrade corporate debt is considered a Level 2B asset, while bank loans do not count as HQLA. In turn, we choose parameters $\nu_{b}=1.0, \nu_{s, 1}=1.1$, which implies only a modest amount of convexity (which can be interpreted as low holding costs), and $\nu_{s, 2}=1.15$, indicating that these securities have greater regulatory/holding costs. ${ }^{21}$ We parameterize $\Delta_{s, 2}$ so that the difference in spreads between the two types of firms is 0 in steady-state. We set $S_{h, 1}^{-}$and $\kappa_{s, 1}$ to the values of private securities in Gertler and Karadi (2013).

For intermediate good firms, we set the returns to scale parameter parameter to 0.95. We set the share of labor and output in production of type 1 firms to 0.5. This is an overestimate for the U.S., and thus our estimate (at least as a function of these parameters) is an upper bound of the positive effect of stimulus on large firms on overall output.

\footnotetext{
${ }^{21}$ Our results are qualitatively similar if we set $\nu_{s, 2}=\nu_{s, 1}$.
} 


\begin{tabular}{lc}
\hline \hline Parameters & Value \\
\hline From Gertler and Karadi (2013) & \\
Households & 0.995 \\
Discount rate, $\beta$ & 0.815 \\
Habit parameter, $h$ & 3.482 \\
Relative utility weight of labor, $\chi$ & 0.450 \\
Steady-state Treasury supply, $B / Y$ & 0.750 \\
$\quad$ Proportion of long-term Treasury holdings of the households, $\bar{B}^{h} / B$ & 1.000 \\
Portfolio adjustment cost, $\kappa$ & 0.276 \\
Inverse Frisch elasticity of labor supply, $\varphi$ & \\
Financial Intermediaries and Households & 0.345 \\
Fraction of capital that can be diverted, $\theta$ & 0.500 \\
Proportional advantage in seizure rate of government debt, $\Delta$ & 0.0062 \\
Transfer to the entering bankers, $X$ & 0.972 \\
Survival rate of the bankers, $\sigma$ & \\
Intermediate Good Firms & 0.330 \\
Capital share, $\alpha$ & 0.025 \\
Depreciation rate, $\delta$ & \\
Capital-Producing Firms & 1.728 \\
Inverse elasticity of net investment to the price of capital, $\eta_{i}$ & \\
Retail Firms & \\
Elasticity of substitution, $\epsilon$ & 4.167 \\
Probability of keeping the price constant, $\gamma$ & 0.779 \\
Government & \\
Steady-state proportion of government expenditures, $G / Y$ & 0.200 \\
Inflation coefficient in the Taylor rule, $\kappa_{\pi}$ & 1.500 \\
Markup coefficient in the Taylor rule, $\kappa_{X}$ & -0.125 \\
New Parameters & \\
Financial Intermediaries and Households & \\
Regulatory constraint parameter on government debt, $\nu_{b}$ & \\
Regulatory constraint parameter on type 1 securities, $\nu_{s, 1}$ & 1.000 \\
Regulatory constraint parameter on type 2 securities, $\nu_{s, 2}$ & 1.100 \\
$\Delta_{s, 2}$, & 1.150 \\
$K_{h}, 1 / K_{1}$, & 1.0531 \\
$K_{h, 2} / K_{2}$, & 0.2 \\
$\kappa_{s, 1}$, & 0.2 \\
$\kappa_{s, 2}$, & 1 \\
Intermediate Good Firms & \\
Returns to scale parameter, $\varsigma$ \\
Type 1 labor share in production \\
Type 2 labor share in production & \\
\hline \hline & \\
\hline
\end{tabular}

Table 1: Parameters 
(a) Central Bank Purchases

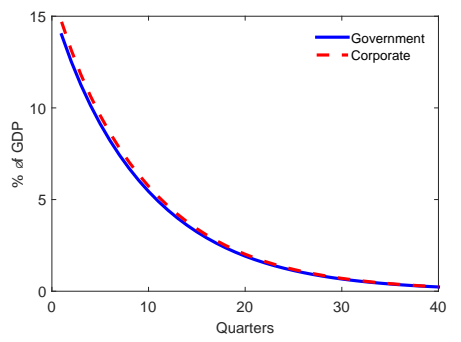

(d) $K$



(g) $E\left[R_{K, 1, t}\right]-R_{t}$

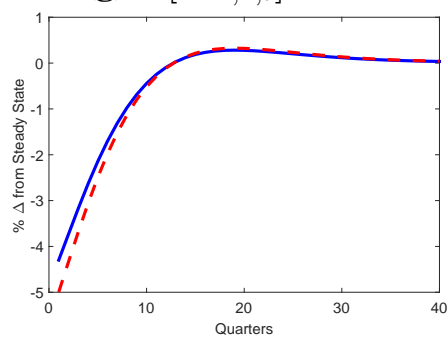

(j) $E\left[R_{K, 2, t}\right]-E\left[R_{K, 1, t}\right]$

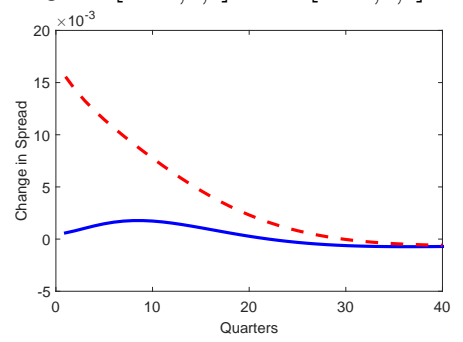

(b) $Y$

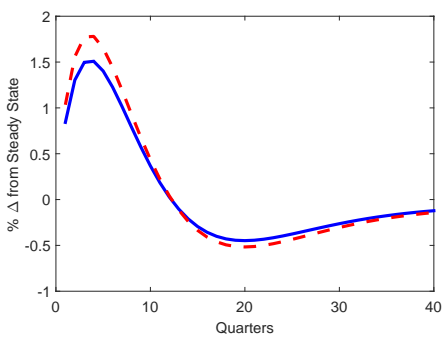

(e) $K_{1}$

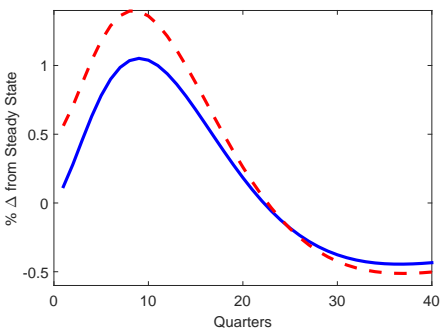

(h) $E\left[R_{K, 2, t}\right]-R_{t}$

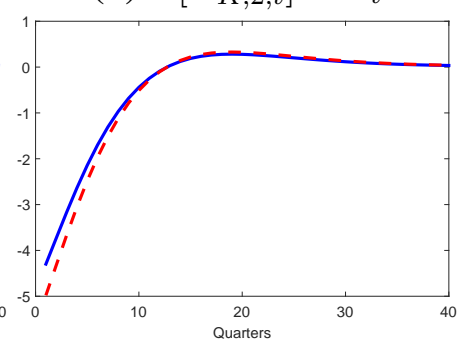

(k) $S_{b, 1}$

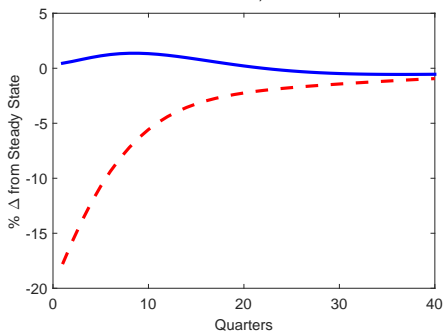

(c) $L$

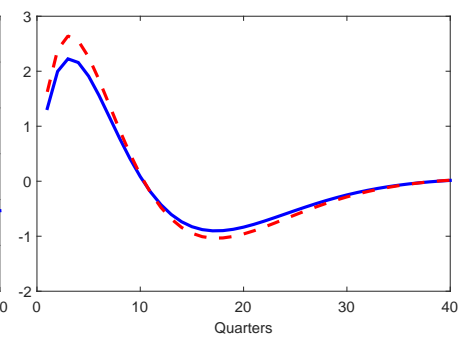

(f) $K_{2}$

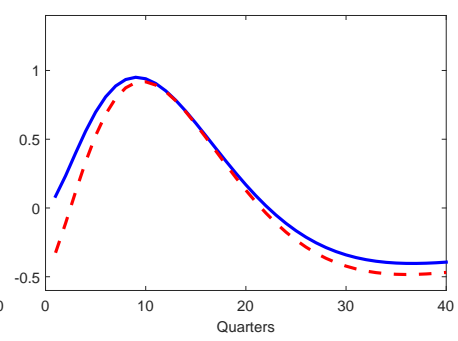

(i) $R_{t}$

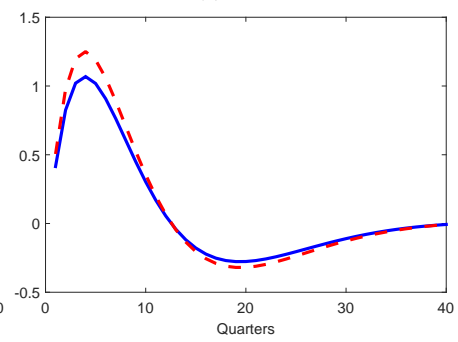

(l) $S_{b, 2}$

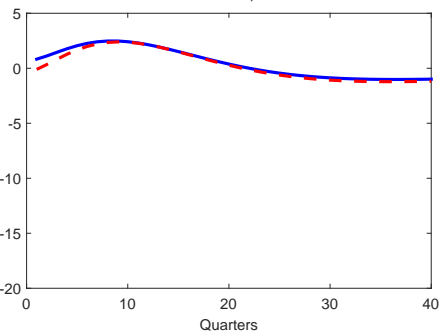

Figure 1: Government and Private Sector Asset Purchase Shocks

\subsection{Quantitative Results}

Figure 1 presents results from the impulse responses from type 1 (large) firm bond purchases and government bond purchases. We see that after a government 




Figure 2: Misallocation Effect and Difference in LSAP Effectiveness

bond purchase, large and small firm's labor and capital decisions react similarly. Specifically, $K_{j, 1}$ and $K_{j, 2}$ react in a virtually identical manner, which can be seen from the solid blue lines in Figures 1e and 1f. However, after a corporate bond purchase, the effect on the capital stock is asymmetric. In particular, the capital stock falls for type 2 (small) firms (the red dashed line in Figure 1f). There is still a positive effect on output, as the lower average spreads leads to greater capital and labor demand, which more than accounts for the negative effect on small firms.

However, the misallocation induced by Central Bank purchases of large firm corporate bonds can be important when looking at the difference between the effectiveness different types of LSAPs. The blue line in Figure 2 is the difference between the impulse response of output during the large firm bond buy and the impulse response of output during the government bond buy. The dashed red line is the output losses due to misallocation in the corporate bond purchase. The losses due to misallocation in large firm corporate bond buys are, at their peak, around $20 \%$ of the difference between the effects of corporate vs. government bonds buys. In other words, when weighing different LSAP options, the misallocation effect of corporate bond buys should potentially be weighed as part of the trade-offs involved, as it can be quantitatively meaningful. 
Overall, the calibrated impulse responses suggest that an LSAP of corporate bond purchases induces a greater misallocation of resources for a corporate bond purchase than a government bond buy

\section{Zero-lower Bound Discussion and Conclusion}

In our model, when at the zero-lower bound (ZLB), output losses from exogenous shocks are exacerbated. ${ }^{22}$ To demonstrate the implications of the ZLB for misallocation, we feed in shocks that force the economy to the effective ZLB and compare the reaction of aggregates and misallocation costs with and without an effective lower bound constraint in response to a large-scale corporate bond buy (that occurs in the fifth quarter). ${ }^{23}$ We see from Figure 3 that our misallocation measure does not drastically change in response to corporate bond buys when we allow for a ZLB (it does rise slightly more as capital of type 2 firms falls by more than in the non-ZLB case and type 1 capital rises slightly more).

However, it is important to note that capital and output are falling by much more when the ZLB is present, a standard result also consistent with Gertler and Karadi (2013). Hence, misallocation matters much more relative to movements in real output when the ZLB is not binding. There are some that present arguments that QE should be part of the central bank toolkit even away from the ZLB (see Quint and Rabanal (2017), e.g.). Our ZLB exercise thus sheds light on a potential counterargument to be considered when making such a claim, at least for large-scale corporate bond buys.

Overall, this paper demonstrates that large-scale purchases of nonfinancial corporate bonds can induce a misallocation of resources. The quantitative results from a DSGE model that builds on Gertler and Karadi (2013) show that under a reasonable calibration there can be a negative effect on investment of firms whose bonds are not purchased as part of the LSAP program.

\footnotetext{
${ }^{22}$ To incorporate the ZLB in our model, we follow the work (and use the code) of Guerrieri and Iacoviello (2015).

${ }^{23}$ Note that the misallocation measure will be slightly different in magnitude as compared to the magnitude implied by backing out the magnitude of the measures from Figures 1e and $1 \mathrm{f}$ as we feed in slightly different shocks to perform this exercise.
} 


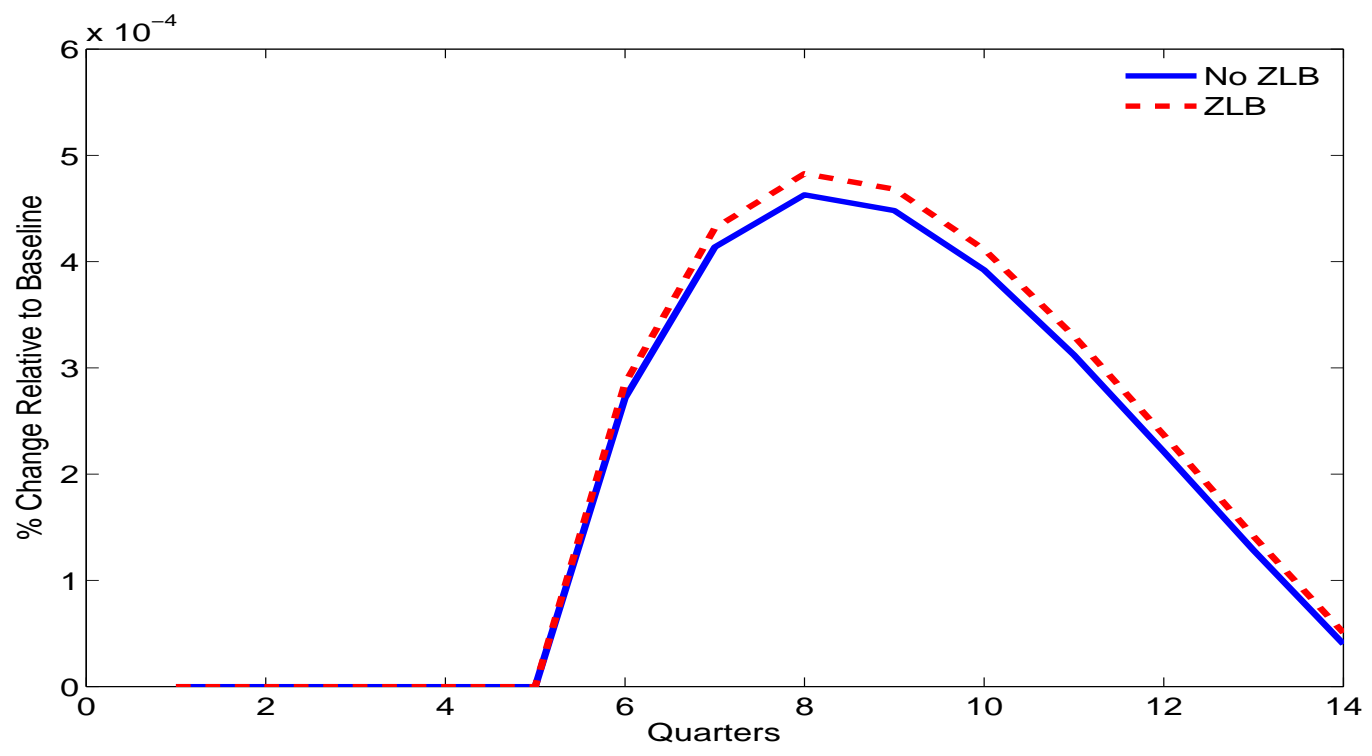

Figure 3: Misallocation Effect of Large-Scale Corporate Bond Buy with and without the ZLB

\section{A Proofs to Propositions}

Here, we present short proofs to our propositions.

\section{Proposition 1}

We can express the Lagrangian multiplier term in spreads as:

$$
\frac{\lambda}{1+\lambda}=\frac{\sum_{j} \theta \Delta_{j}\left(Q K_{j}-S_{g, j}\right)^{\nu_{j}}+\left(B_{b}^{T}-B_{g}\right) \theta-N * r}{\sum_{j} \theta \Delta_{j} \nu_{j}\left(Q K_{j}-S_{g, j}\right)^{\nu_{j}}+\left(B_{b}^{T}-B_{g}\right) \theta} .
$$

This derivative of (25) with respect to $B_{g}$, holding capital choices (and therefore $\left.K_{j}, Q\right)$, constant yields:

$$
-\frac{\theta\left(\sum_{j} \theta \Delta_{j}\left(\nu_{j}-1\right)\left(Q K_{j}-S_{g, j}\right)^{\nu_{j}}+N * r\right)}{\left(\sum_{j} \theta \Delta_{j} \nu_{j}\left(Q K_{j}-S_{g, j}\right)^{\nu_{j}}+\left(B_{b}^{T}-B_{g}\right) \theta\right)^{2}}<0,
$$

which implies (i)(a) (since $\frac{\lambda}{1+\lambda}$ is increasing in $\lambda$ ). (i)(b) follows immediately from (4). 
Similarly, (ii)(a) follows from taking the derivative of $\frac{\lambda}{1+\lambda}$ with respect to $S_{g, i}$ for $i \in * j$, holding capital choices constant, and (ii)(b) immediately follows from (4).

\section{Proposition 2}

Note that output, defined in (9), is increasing in the term $\int_{i}\left(A_{i}^{\lambda}\left(\frac{r_{\tau, i}}{\tau_{i}^{i}}\right)^{\alpha \lambda}\right)^{\frac{1}{1-\alpha \lambda}} d i$. The output maximizing value for interest rate wedges then can be found by solving the maximization problem:

$$
\max _{r_{\tau, i}} \int_{i}\left(A_{i}^{\lambda}\left(\frac{r_{\tau, i}}{\tau_{i}^{k}}\right)^{\alpha \lambda}\right)^{\frac{1}{1-\alpha \lambda}} d i
$$

such that

$$
\frac{\left(\int\left(\frac{A_{i}^{\lambda}}{\left(\tau_{i}^{k}\right)^{\alpha \lambda}}\right)^{\frac{1}{1-\alpha \lambda}}\left(r_{\tau, i}\right)^{\frac{\alpha \lambda}{1-\alpha \lambda}} d i\right)^{\frac{1-\lambda}{\lambda}}\left(\int\left(\frac{A_{i}^{\lambda}}{\tau_{i}^{k}}\right)^{\frac{1}{1-\alpha \lambda}}\left(r_{\tau, i}\right)^{\frac{1}{1-\alpha \lambda}} d i\right)^{1-\alpha}}{\left(\int\left(\frac{A_{i}^{\lambda}}{\left(\tau_{i}^{k}\right)^{\alpha \lambda}}\right)^{\frac{1}{1-\alpha \lambda}} d i\right)^{\frac{1-\lambda}{\lambda}}\left(\int\left(\frac{A_{i}^{\lambda}}{\left(\tau_{i}^{k}\right)}\right)^{\frac{1}{1-\alpha \lambda}} d i\right)^{1-\alpha}}=1 .
$$

This yields a first-order condition which can be simplified to be of the form $\frac{r_{\tau, i}}{\tau_{i}^{k}}=\Xi$, where $\Xi$ is a constant across firms. Proposition 2 follows.

\section{References}

Saroj Bhattarai, Gauti B Eggertsson, and Bulat Gafarov. Time consistency and the duration of government debt: A signalling theory of quantitative easing. National Bureau of Economic Research Working Paper No. 21336, 2015.

Vasco Cúrdia and Michael Woodford. Credit frictions and optimal monetary policy. National Bureau of Economic Research Working Paper No. 21820, 2015.

Mark Gertler and Peter Karadi. A model of unconventional monetary policy. Journal of monetary Economics, 58(1):17-34, 2011. 
Mark Gertler and Peter Karadi. Qe 1 vs. 2 vs. 3...: A framework for analyzing large-scale asset purchases as a monetary policy tool. International Journal of Central Banking, 9(1):5-53, 2013.

Simon Gilchrist, Jae W. Sim, and Egon Zakrajsek. Misallocation and financial market frictions: Some direct evidence from the dispersion in borrowing costs. Review of Economic Dynamics, 16:159-176, 2013.

Robin Greenwood and Dimitri Vayanos. Bond supply and excess bond returns. Review of Financial Studies, 27(3):663-713, 2014.

Luca Guerrieri and Matteo Iacoviello. Occbin: A toolkit for solving dynamic models with occasionally binding constraints easily. Journal of Monetary Economics, 70:22-38, 2015.

Zhiguo He and Arvind Krishnamurthy. Intermediary asset pricing. The American Economic Review, 103(2):732-770, 2013.

Hugo A. Hopenhayn and Richard Rogerson. Job turnover and policy evaluation: A general equilibrium analysis. Journal of Political Economy, 101(5):915-938, October 1993.

Chang-Tai Hsieh and Peter J Klenow. Misallocation and manufacturing tfp in china and india. The Quarterly Journal of Economics, 124(4):1403-1448, 2009.

Arvind Krishnamurthy and Annette Vissing-Jorgensen. The effects of quantitative easing on interest rates: Channels and implications for policy. Brookings Papers on Economic Activity, 2011.

Virgiliu Midrigan and Daniel Yi Xu. Finance and misallocation: Evidence from plant-level data. American Economic Review, 104:422-458, 2014.

Dominic Quint and Pau Rabanal. Should unconventional monetary policies become conventional? IMF Working Paper No. 17/85, 2017. 
Volker Wieland, Tobias Cwik, Gernot J. Mller, Sebastian Schmidt, and Maik Wolters. A new comparative approach to macroeconomic modeling and policy analysis. Journal of Economic Behavior and Organization, 2015.

Volker Wieland, E. Afanasyeva, M. Kuete, and J. Yoo. New methods for macrofinancial model comparison and policy analysis. Handbook of Macroeconomics, 2, Forthcoming. 